\title{
Were endophytes pre-adapted for defensive mutualism?
}

\author{
M.S.TORRES ${ }^{1 *}$, A.P. SINGH ${ }^{1,2}$, N. VORSA ${ }^{2,1}$, T. GIANFAGNA ${ }^{1}$ and J.F.WHITE Jr. \\ ${ }^{1}$ Department of Plant Biology and Pathology, Rutgers University, 59 Dudley Road, New Brunswick, New Jersey 08901 \\ ${ }^{2}$ Marucci Blueberry-Cranberry Research Center, Rutgers University, 125a Lake Oswego Road, Chatsworth, NJ 08019 \\ *mstorres2001@yahoo.com,mstorres@eden.rutgers.edu
}

\begin{abstract}
Defensive mutualism in many grass endophytes involves herbivore deterrence, enhanced disease suppression and drought tolerance. According to our current understanding of the mechanisms, these defensive effects are unique features of the fungi and specific fungal qualities are responsible for each. We examined a selection of species of family Clavicipitaceae for defensive traits including ergot alkaloids and loline production and development of endophytic and epiphytic mycelial states. When features responsible for defensive effects are mapped onto phylogenetic trees showing relationships in the family, it is apparent that all defensive features of endophytic fungi pre-existed evolution of endophytism. We suggest that once endophytism evolved, the alkaloids and other fungal-mediated defensive features switched from previous functions to serve host defense functions. Defensive mutualism in the Clavicipitaceae endophytes naturally evolved through use of pre-existing fungal features after the step to endophytism was made.
\end{abstract}

Keywords: Clavicipitaceae, defensive mutualism, endophytes, ergot alkaloids, loline alkaloids

\section{Introduction}

Defensive mutualism in the Clavicipitaceae (Hypocreales, Ascomycota) is a concept that was first articulated by Keith Clay to explain deterrent effects of endophytes primarily against insects. Based on experiments that demonstrated that insects show a feeding preference for endophyte-free grasses, it was proposed that defense of the host plant from herbivores was an important ecological function of endophytes (Clay 1988). Observations on certain endophyte-infected grasses also suggested that endophytes protected grasses from herbivores in general, such as prairie voles (Microtus ochrogaster) (Durham \& Tannenbaum 1998) and avian passerines (Madej \& Clay 1991). In vertebrates grazing endophyte-infected tall fescue and perennial ryegrass, toxicoses including "fescue foot" and "ryegrass staggers" are common occurrences. Secondary metabolites produced by the endophytes are responsible for anti-herbivore effects. These metabolites include ergot alkaloids, lolines, peramine and other metabolites, not all of which have been fully characterised (Porter 1994).

Our understanding and interpretation of defensive mutualism as it pertains to endophytes in Clavicipitaceae has become more elaborate as a more complete knowledge of endophyte effects on grass hosts has developed. The defensive mutualism concept was expanded to include defense of the host from abiotic effects when it became clear that some endophytes imparted enhanced tolerance to drought (West et al. 1990; Malinowski \& Belesky 2000). More recently it has been proposed that certain endophytes also benefit hosts by defending them from some foliar pathogens. Clarke et al. (2006) showed that in the fine and hard fescues endophyte-mediated suppression of the leaf spot disease "dollar spot" caused by the fungus Sclerotinia homeocarpa is commonly observed. In addition, Bonos et al. (2005) also have shown endophyte-mediated resistance to "red thread disease" caused by Laetisaria fuciformis in fine fescues. From an evolutionary perspective it is of interest to evaluate whether the defensive features of grass endophytes evolved de novo when the endophytes evolved or instead pre-existed evolution of the grass endophytes and were present in species that were ancestral to the Epichloë/ Neotyphodium endophyte.

Our hypothesis is that endophytes in Clavicipitaceae were preadapted for defensive mutualism symbiosis with host plants. The characteristics we attribute to defense of hosts pre-existed any host defensive function. Once endophytism evolved the pre-adaptive characteristics of the fungi naturally gave way to defensive mutualisms now evident among endophytic species. To illustrate this argument we analysed and placed in a phylogenetic context each of the beneficial functions independently, alkaloid production (ergot alkaloids and loline alkaloids), endophytemediated disease suppression and enhanced drought tolerance.

\section{Materials and Methods}

\section{Phylogenetic analysis}

To analyse phylogenetic relationships LSU rDNA sequences of a selection of species representing the family Clavicipitaceae were selected (Table 1), aligned and analysed using the program PAUP v 4.0 (Swofford 2002) by maximum likelihood and Bayesian analysis. ModelTest v.3.06 (Posada \& Crandall 1998) was used to select the best fitting model of sequence evolution determined by Akaike information criterion (Akaike 1974).

The model selected was TRN with proportion of invariable sites (I) and gamma distribution $(\mathrm{G})$. The parameters include base frequencies $\mathrm{A}=0.2628, \mathrm{C}=0.2197, \mathrm{G}=0.3375, \mathrm{~T}=0.1799$; rate matrix $[\mathrm{A}-\mathrm{C}]=1.0,[\mathrm{~A}-\mathrm{G}]=2.0369,[\mathrm{~A}-\mathrm{T}]=1.0,[\mathrm{C}-\mathrm{G}]=1.0$, $[\mathrm{C}-\mathrm{T}]=10.1208 ;[\mathrm{G}-\mathrm{T}]=1.0 ; \mathrm{I}=0.4879$ and $\mathrm{G}=0.5224$ and this model was incorporated into PAUPv.4.0. The most likely tree (-ln 3877.97) is shown in Fig. 1. Bayesian inference was used to estimate branch support (posterior probability) under likelihood using Mr Bayes 3.0 (Huelsenbeck 2000). Bayesian analysis was run three times with four mcmc (Markov Chain Monte Carlo) chains for 1,000,000 generations, sampling every 100 generations. The 30,000 trees resulting from the three runs were pooled and 28,500 were imported into PAUP to construct a majority rule consensus tree after discarding the asymptotic trees (burn in).

\section{Alkaloids analyses}

Twelve species were subjected to alkaloid analysis (Table 1). For ergot alkaloid analysis fungal extracts were subjected to high performance liquid chromatography (HPLC) and mass spectrophotometry (LC-MS) analyses following procedures of Torres et al. (2006). For loline analysis, fungal extracts were subjected to gas chromatography-mass spectroscopy (GC-MS) analysis (Blankenship et al. 2001; Yates et al. 1990). The results were mapped into a phylogenetic tree (Fig. 1).

\section{Results and Discussion}

\section{Alkaloid production and herbivore deterrence}

Secondary metabolites produced in grass-endophyte associations are generally assumed to be defensive in function (Panaccione 
Figure. 1 The most likely tree (-In (-LN 3877.97) as determined by Paup using TrN+l+G model of evolution. Numbers on the branches indicate posterior probabilities as a percentage for the node they proceed (only $\geq 50 \%$ shown). (Symbols, + ergot alkaloids, * lolines).

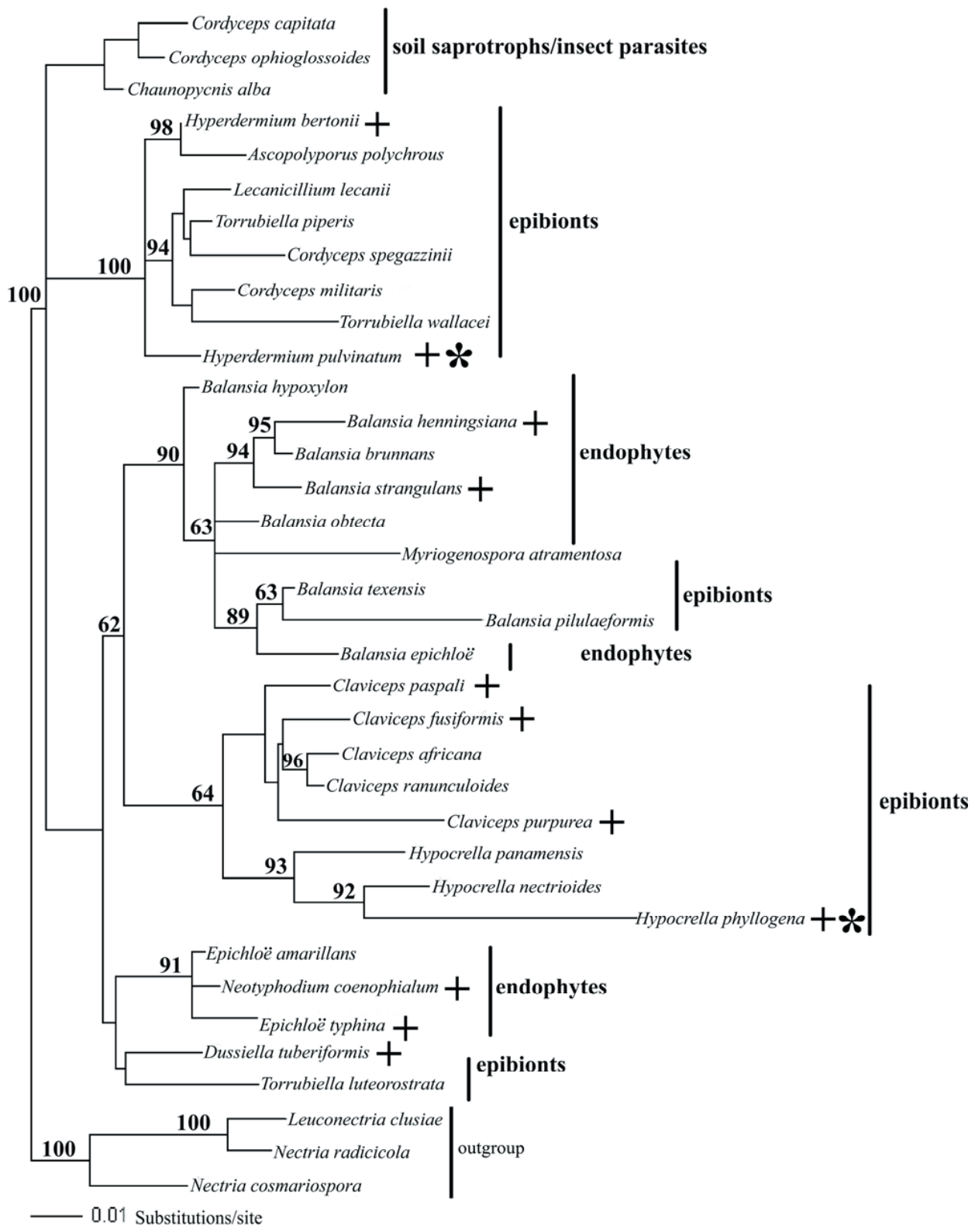

\& Schardl 2003). Generally an array of alkaloids and other secondary metabolites are produced by the endophyte in each symbiotic association suggesting a spectrum of biological activities (Panaccione 2005). It is also reasonable to assume that there are synergisms of these compounds with one another. Ergot alkaloids (ergonovine and derivates) and lolitrems have been associated with vertebrate toxicity (Schardl \& Philips 1997). Ergot alkaloids have also been shown to deter feeding by mammals (Panaccione et al. 2006).

Lolines and possibly peramine have been mainly associated with insect toxicity (Porter 1994). It has been shown that aphids (Rhopalosiphum padi), Japanese beetle (Popillia japonica), fall armyworm (Spodoptera frugiperda), and several other insects are deterred from feeding by lolines (Wilkinson et al. 2000; Riedell et al. 1991; Patterson et al. 1991).

Because Dussiella, Hyperdermium and Hypocrella are deeply rooted epibionts in phylogenetic analyses (see Fig. 1) and they also possess ergot alkaloids it is evident that ergot alkaloids are a feature that pre-existed the evolution of endophytism and defensive mutualism with the host plant.

\section{Function switching}

It is unlikely that alkaloids in the non endophytic species of Clavicipitaceae play any role in defense of their host plants. 
Table 1 Large subunit ribosomal DNA sequences included in phylogenetic analysis and alkaloid analysis

\begin{tabular}{|c|c|c|}
\hline Taxa & LSU & Alkaloid \\
\hline Ascopolyporus polychrous Møller & AY886547 & RUTTP-JB211 \\
\hline Balansia brunnans Lewis \& White & AY3207046 & - \\
\hline Balansia epichloë (Weese) Diehl & U68121 & - \\
\hline Atkisonella hypoxylon (Peck) Diehl & U57087 & - \\
\hline Balansia henningsiana (Møller) Diehl & U57678 & - \\
\hline Balansia nigricans Diehl & - & RUTTP-BN1 \\
\hline Balansia obtecta Diehl & U68120 & - \\
\hline Balansia strangulans (Mont.) Diehl & U57679 & CBS334.96 \\
\hline Atkinsonella texensis (Diehl) Leuchtm. \& Clay & U68113 & - \\
\hline Balansia pilulaeformis (Berk. \& M.A. Curtis) Diehl & AF543788 & - \\
\hline Chaunopycnis alba Gams & AF245296 & RUTTP-GB1 \\
\hline Claviceps africana Freder., Mantle \& De Milliano & AF245294 & - \\
\hline Claviceps fusiformis Loveless & U17402 & - \\
\hline Claviceps paspali Stevens \& J.G. Hal & U47826 & - \\
\hline Claviceps purpurea (Fr.) Tul & U57085 & sclerotia \\
\hline Claviceps ranunculoides Møller & AF245295 & - \\
\hline Cordyceps capitata (Holmsk.) Link & U57086 & - \\
\hline Cordyceps militaris (L.) Link & AF043135 & - \\
\hline Cordyceps ophioglossoides (Ehrh.) Link & U47827 & - \\
\hline Cordyceps spegazzinii Torres et al. & DQ196435 & MYA3684 \\
\hline Dussiella tuberiformis (Berk. \& Ravenel) Pat & U57083 & MYA 2810 \\
\hline Epichloë amarillans White & U57680 & - \\
\hline Epichloë typhina (Pers.:Fr.) Tul. & U17396 & - \\
\hline Hyperdermium bertonii White et al. & AF242354 & - \\
\hline Hyperdermium pulvinatum White et al. & AF242353 & RUTTP-HP1 \\
\hline Hypocrella panamensis Torres et al. & DQ127242 & RUTTP-JB207 \\
\hline Hypocrella nectrioides Thaxt & U47832 & - \\
\hline Hypocrella phyllogena (Mont.) Speg & AY518372 & RUTTP-4iso8 \\
\hline Lecanicillium lecanii (Zimmermann) Zare et Gams & U17414 & - \\
\hline Leuconectria clusiae (Samuels \& Rogerson) Rossman et al.U17412 & - & \\
\hline Nectria cosmariospora Ces. \& De Not. & U17407 & - \\
\hline Nectria radicicola Gerlach \& L. Nilsson & U17415 & - \\
\hline Neotyphodium coenophialum & AF160241 & - \\
\hline Paecilomyces lilacinus & - & GB-5470 \\
\hline Torrubiella piperis Bischoff \& White & AY466442 & - \\
\hline Torrubiella wallacei Evans & AY184967 & - \\
\hline Torrubiella luteorostrata Zimm. & AY554252 & - \\
\hline Torrubiella superficialis Zimm. & - & RUTTP-SU70 \\
\hline
\end{tabular}

This is because these fungi are not systemic in host plants and alkaloids likely remain within the restricted superficial mycelia. Their functions in the superficial fungal mycelia are unknown and it could be assumed that they protect the stromata from insect herbivory (Torres et al. unpublished). Regardless of their function, it is apparent that epibiotic species in the Clavicipitaceae were pre-adapted for defensive mutualism by production of compounds that now serve to deter herbivore feeding. We propose that once the fungi evolved as systemic endophytes, ergot alkaloids switched function from "self defense" of stromata to "host defense".

Lolines were detected in species including Hyperdermium pulvinatum and Hypocrella phyllogena (Fig. 1). Both these species are epibiotic and more deeply rooted in the phylogenetic analysis than endophytic species of Epichloë and Balansia. It seems likely that lolines also occur in additional species of Clavicipitaceae, although we did not detect it. Previous work with lolines suggests that it is infrequently expressed in culture (Blankenship 2004). The discovery of lolines in other more deeply rooted members of the family suggests that the defensive compound loline preexisted evolution of the endophytes and may be a compound that is common in the family.

Another alkaloid that is important in the endophyte defensive mutualism is peramine. This compound is believed to be detected by some insects that feed on the aboveground grass plants. Future studies will be needed to evaluate whether peramine was newly evolved in the endophytes or is another feature that is common in the family Clavicipitaceae. 


\section{Enhanced fungus disease resistance}

Endophytes in fine and hard fescues where enhanced disease resistance has been demonstrated also possess an epibiotic or epiphyllous phase where mycelium forms a dense network on surfaces of leaf blades. The superficial mycelium on leaf blades was termed "defensive nets" by Moy et al. (2000). In addition to fine and hard fescue, epiphyllous mycelia have been found on numerous additional endophyte infected grasses including Agrostis hiemalis, Poa rigidifolia and Hordeum brevisubulatum (White et al. 1996; Dugan et al. 2002).

Circumstantial evidence suggests that endophyte-mediated resistance to fungal disease is due to a competitive exclusion phenomenon. Epiphyllous mycelia on leaf blades occupy a niche that many pathogens must colonize prior to entering leaves to incite disease. The plant epiphytic condition is more primitive or more deeply rooted than the endophytic condition in family Clavicipitaceae (See Fig. 1). Scale insect parasite/plant epibiont species (including Hyperdermium, Dussiella and Torrubiella) are among the most deeply-rooted in phylogenetic analysis (Fig. 1). These species infect scale insects, degrade them and live biotrophically as epiphytes that are nourished by nutrients that leak to the plant surface through the stylet wound (Koroch et al. 2004). It seems probable that such epiphytic states were ancestral to acquisition of endophytism in genera such as Epichloe and Balansia. In the Balansia clade, the epiphytic species $B$. hypoxylon, and $B$. texensis are more deeply rooted than endophytic species $B$. hennigsiana, B. strangulans and $B$. nigricans. The epibiotic species in Balansia grow superficially on the meristematic surfaces of plants. The epiphyllous condition thus pre-existed acquisition of endophytism in the family.

The endophytes that retain an epiphyllous state tend to be those that grow aggressively and colonise developing leaves internally and externally. These are frequently endophytes that retain the capacity to sexually reproduce using stromata but some that do not produce stromata also develop epiphyllous mycelia. The endophytes of Neotyphodium lolii and N. coenophialum in perennial ryegrass and tall fescue, respectively, do not produce epiphyllous mycelial states and have not shown any disease resistance to leaf spot diseases. The endophytes retaining the primitive epiphyllous feature are the ones that demonstrate fungus disease resistance. The epiphytic condition of the plant biotrophic epibionts pre-adapted the endophytes for defense against some plant pathogens.

\section{Physiological mechanisms: drought tolerance}

Little is clearly understood regarding the mechanisms involved in drought tolerance. One hypothesis of the mechanism involves osmotic adjustment of the meristematic tissues where endophytes reside in the intercellular spaces (Elmi \& West 1995). In this phenomenon it has been suggested that osmotically active metabolites such as water-soluble sugars, mannitol, and amino acids like proline and alkaloids (lolines) accumulate in intercellular spaces of the meristems and cause a pre-acclimation to drought conditions (Richardson et al. 1992; Richardson 2000).

If the osmotic adjustment hypothesis for enhanced drought tolerance is correct then the endophytes may also have been preadapted for osmotic adjustment of host meristems by production and secretion of alkaloids and release of other metabolites. Endophytes may also cause some release or leakage of nutrients from host cells and this may contribute to the osmotic adjustment effects.

\section{Conclusions}

Our analysis suggests that fungal features responsible for defensive mutualism in the grass endophytes evolved prior to evolution of endophytism in genera Balansia, Epichloë and Neotyphodium. This suggests that the family was pre-adapted to develop defensive mutualisms once systemic endophytisms evolved. It is apparent that after evolution of endophytism, compounds, physiological processes, and mycelial structures switched from whatever were their previous functions to defense of the host plant.

\section{REFERENCES}

Akaike, H. 1974. A new look at the statistical model identification. IEEE Transactions on Automatic Control 19: 716-723.

Blankenship, J.D. 2004. Loline alkaloid biosynthesis in Neotyphodium uncinatum, a fungal endophyte of Lolium pratense. Ph.D. Dissertation. University of Kentucky, 97 pp.

Blankenship, J.D.; Spiering, M.J.; Wilkinson, H.H.; Fannin, F.F.; Bush, L.P.; Schardl, C.L. 2001. Production of loline alkaloids by grass endophyte, Neotyphodium uncinatum, in defined media. Phytochemistry 58: 395-401.

Bonos, S.A.; Wilson, M.M.; Meyer, W.A.; Funk, C.R. 2005. Suppression of red thread in fine fescues through endophytemediated resistance. Online. Applied Turfgrass Science doi:10.1094/ATS-2005-0725-01-RS.

Clarke, B.B.; White, J.F.Jr.; Hurley, R.H.; Torres, M.S.; Sun, S.; Huff, D.R. 2006. Endophyte-mediated suppression of dollar spot disease in fine fescues. Plant Disease 90: 994-998.

Clay, K. 1988. Fungal endophytes of grasses: a defensive mutualism between plants and fungi. Ecology 69: 10-16.

Dugan, F.M.; Sitton, J.; Sullivan, R.F.; White, J.F.Jr. 2002. The Neotyphodium endophyte of wild barley (Hordeum brevisubulatum subsp. violaceum) grows and sporulates on leaf surfaces of the host. Symbiosis 32: 147-159.

Durham, W.F.; Tannenbaum, M.G. 1998. Effects of endophyte consumption on food intake, growth, and reproduction in prairie voles. Canadian Journal of Zoology 76(5): 960-969.

Elmi, A.A.; West, C.P. 1995. Endophyte effects on tall fescue stomatal response, osmotic adjustment, and tiller survival. New Phytologist 13: 61-67.

Huelsenbeck, J.P. 2000. MrBayes: Bayesian inference of phylogeny. Distributed by the author. Department of Biology, University of Rochester.

Koroch, A.; Juliani, H.; Bischoff, J.; Lewis, E.; Bills, G.; Simon, J.; White, J.F.Jr. 2004. Examination of plant biotrophy in the scale insect parasitizing fungus Dussiella tuberiformis. Symbiosis 37: 267-280.

Madej, C.W.; Clay, K. 1991. Avian seed preference and weight loss experiments: the effect of fungal endophyte-infected tall fescue seeds. Oecologia 88: 296-302.

Malinowski, D.O.; Belesky, D.P. 2000. Adaptations of endophyteinfected cool season grasses to environmental stresses: mechanisms of drought and mineral stress tolerance. Crop Science 40: 923-940.

Moy, M.; Belanger, F.; Duncan, R.; Freehof, A.; Leary, C.; Meyer, W.; Sullivan, R.; White, J.F.Jr. 2000. Identification of epiphyllous mycelial nets on leaves of grasses infected by clavicipitaceous endophytes. Symbiosis 28: 291-302.

Panaccione, D. G. 2005. Origins and significance of ergot alkaloid diversity in fungi. FEMS Microbiology letters, 251:9-17.

Panaccione, D.G., Cipoletti, J.R.; Sedlock, A.B.; Blemings, K.P.; Schardl, C.L.; Machado, C.;

Seigel, G. 2006. Effects of ergot alkaloids on food preference and satiety in rabbits, as assessed with gene-knockout endophytes in perennial ryegrass (Lolium perenne). Journal of Agriculture and Food Chemistry 54(13): 4582-4587. 
Panaccione, D.G.; Schardl, C.L. 2003. Molecular genetics of ergot alkaloid biosynthesis pp. 399-443. In: Clavicipitalean Fungi: Evolutionary Biology, Chemistry, Biocontrol and Cultural Practices. Eds White, J.F.; Bacon, C.W.; HywelJones, N.L.; Spatafora, J.W. Marcel Dekker, New York.

Patterson, C.G.; Potter, D.A.; Fanin, F.F. 1991. Feeding deterrence of alkaloids from endophyte-infected grasses to Japanese beetle grubs. Entomologia. Experimentalis et Aplicata 61: 285-289.

Porter, K.J. 1994. Chemical constituents of grass endophytes pp. 103-124. In: Biotechnology of endophytic fungi of grasses. Eds. Bacon, C.W.; White, J.F. Marcel Dekker, New York.

Posada, D.; Crandall, K.A. 1998. Modeltest: testing the model of DNA substitution. Bioinformatics 14: 817-818.

Richardson, M.D.; Chapman, G.W. Jr.; Hoveland, C.S.; Bacon, C.W. 1992. Sugar alcohols in endophyte infected tall fescue. Crop Science 32: 1060-1061.

Richardson, M.D. 2000. Alkaloids of endophyte-infected grasses: defensive chemicals or biological anomalies pp. 323-340. In: Microbial endophytes. Eds. Bacon, C.W.; White, J.F. Marcel Dekker, New York.

Riedell, W.E.; Kieckhefer, R.E.; Petroski, R.E.; Powell, R.G. 1991. Naturally occurring and synthetic loline alkaloids derivatives: insect feeding behavior modification and toxicity. J. Entomological Science. 26: 122-129.
Schardl, C.L.; Phillips, T.D. 1997. Protective grass endophytes: where are they from and where are they going? Plant Disease 81: 430-437.

Swofford, D.L. 2002. PAUP*. Phylogenetic analysis Using Parsimony (*and Other Methods), Version 4. Sinauer Associates, Sunderland, Massachusetts.

Torres, M.S.; Singh, A; Vorsa, N.; White, JFJr. Distribution and significance of ergot alkaloids in the fungal family Clavicipitaceae (Hypocreales, Ascomycota). Submitted to Organisms Diversity \& Evolution.

West, C.P.; Oosterhuis, D.M.; Wullschleger, S.D. 1990. Osmotic adjustment in tissues of tall fescue in response to water deficit. Environment and Experimental Botany. 30:149-156.

White, J.F.Jr.; Martin, T.I.; Cabral, D. 1996. Endophyte-host associations in grasses. XXIII. Conidia formation by Acremonium endophytes in the phylloplanes of Agrostis hiemalis and Poa rigidifolia. Mycologia 88: 174-178.

Wilkinson, H.H.; Siegel, M.R.; Blankenship, J.D.; Mallory, A.C.; Bush, L.P.; Schardl, C.L. 2000. Contribution of fungal loline production to protection from aphids in a grass fungus mutualism. Molecular-Plant Microbe Interactions 13: 1027-1033.

Yates, S.G.; Petroski, R.J.; Powell, R.G. 1990. Analysis of loline alkaloids in endophyte-infected tall fescue by capillary gas chromatography. Journal of Agricultural Food Chemistry 38: $182-185$ 